\title{
Can't See the Wood for the Logframe: Integrating Logframes and Theories of Change in Development Evaluation
}

\author{
Gordon Freer \\ University of the Witwatersrand, Johannesburg \\ Sebastian Lemire \\ University of California, Los Angeles
}

\begin{abstract}
There are numerous ways in which to model the underlying theory of programs. In the context of international development evaluation, the most ubiquitous are likely "logframes" and to some extent "theories of change," both of which may serve to guide program development and management, monitoring, and evaluation. While logframes and theories of change are often developed in parallel, they are rarely fully integrated in their practical application. Drawing on lessons from a recent theory-based evaluation, this article argues that fully integrating the program theory of change within the program logframe provides for a stronger and more holistic understanding of program progress.
\end{abstract}

Keywords: international development, logframe, market development programs, program management, theory-based evaluation, theory of change

Résumé : Il y a de nombreuses façons de modéliser la théorie d'intervention d'un programme. Dans le contexte de lévaluation en développement international, on retrouve plus couramment les "cadres logiques» et, dans une certaine mesure, les "théories du changement ». Les deux peuvent servir à orienter lévaluation, le suivi, la gestion et l'élaboration de programmes. Les cadres logiques et les théories du changement sont souvent élaborés en parallèle, et rarement complètement intégrés. À partir d'une évaluation théorique (theory-based) récente, le présent article montre quien intégrant pleinement la théorie du changement au cadre logique d'un programme, on obtient une représentation plus robuste et plus globale des progrès réalisés par le programme.

Mots clés : développement international, cadre logique, programmes de développement des marchés, gestion des programmes, évaluation fondée sur la théorie, théorie du changement

Corresponding author: Gordon Freer, International Relations, School of Social Sciences,

University of the Witwatersrand, Johannesburg, 2050, South Africa; gordon@insightstrategies.net

( 2019 Canadian Journal of Program Evaluation / La Revue canadienne d'évaluation de programme 33.3 (Special Issue / Numéro special), 336-353 doi: 10.3138/cjpe.53007 
The logframe has been ever present in development circles since its adoption and promotion by the U.S. Agency for International Development (USAID) in the early 1970s. Informed by a review of USAID's evaluation system, the logframe was originally developed as a tool to help conceptualize a project and analyze the assumptions behind it (Rosenberg \& Posner, 1979). Since then, the logical framework approach has undergone cosmetic changes and shifts in terminology; however, its primary purpose remains intact: to demonstrate how parts of a program fit together, neatly and logically, and how a series of program activities will lead to a specific set of program objectives (however we chose to define these). The logframe approach has in many instances proven extremely valuable for project design, planning, implementation, management, monitoring, and evaluation and is now widely used by bilateral and multilateral development agencies as the de facto program-management tool (Bamberger, Rugh, \& Mabry, 2012; Hummelbrunner, 2010; Prinsen \& Nijhof, 2015). The sustained dominance of logframes in international development is illustrated in the UK Department for International Development guidelines for funding applicants, which require that "all newly approved projects regardless of project value must also now contain a logframe" (DFID, 2011, p. 2).

The logframe, when it is designed and used as intended, works well as a monitoring tool to assess program progress against predefined objectives. One central limitation, however, is that logframes often focus on short- and mediumterm objectives, as opposed to detailing how these lead to long-term changes (Bamberger et al., 2012; Channell, 2005). In extension, another limitation is that logframes by design do not provide information on how or why program objectives were reached (or not reached). As Eyben, Kidder, Rowlands, and Bronstein (2008) observe, the "linear cause-effect thinking" inherent to logframes fails to capture the complexity of the change processes underlying most development programs. Herein lies one of the significant assumptions of logframes that has not done evaluation any favours: it is assumed that the logic laid out in the logframe's progressive steps holds true and that an achievement of the program objectives is proof that the program is working according to this logic. This assumption, while seemingly trivial, comes with great consequences, as it leaves the inner workings of how and in what way the program achieves the stated objectives undisclosed and unexamined.

In marked contrast, a theory of change (ToC), also known as program theory, centers exactly on the inner workings of programs (Connell \& Kubisch, 1998). Emerging from the "tradition of logic planning models," such as the logical framework approach, the purpose of the ToC is to make explicit how specific program activities lead to specific outputs, which in turn lead to a specified set of outcomes (Stein \& Valters, 2012, p. 5). Moreover, ToCs-at least the better ones-often consider the external environment of the program and then places the program and its activities within this context, determining how these activities might interact with influencing factors in the broader environment or to what extent competing programs might complement or in some other way influence the program 
activities and outcomes (see Mayne, 2012, for a discussion on "embedded" theories of change).

In providing a more detailed explication of the inner workings of programs, ToCs potentially remedy the limitations associated with logframes described above. For one, ToCs bring attention to the long-term impact of programs, specifying how short- and medium-term outcomes of the development program are at least intended to bring about long-term changes (Prinsen \& Nijhof, 2015). This long-term line-of-sight may potentially serve well to counter the alltoo-common pressure among project managers to focus almost exclusively on monitoring and reporting on short-term program progress (Imas \& Rist, 2009; Prinsen \& Nijhof). Moreover, and in direct relation to logframes, "theory of change thinking," by explicating how specific program activities lead to specific outcomes, may serve "to bridge the 'missing middle' that the log-frame hides" (Vogel, 2012, p. 19).

As the preceding paragraphs illustrate, logframes and theories of change potentially complement and even enhance one another. Unfortunately, and while many development programs involve both a logframe and a theory of change as part of their performance-management framework, the integration of these potentially complementary tools is often challenging (Vogel, 2012). Accordingly, and as Prinsen and Nijhof (2015) conclude, "work remains to be done in order to find ways to optimise the combined use of the logframe and ToC in programming" (p. 244).

Speaking directly to this call, this article makes the case for more purposeful integration of the design and use of logframes and ToCs. More specifically, we argue that integrating these tools in program planning and evaluation enhances both the quantitative measures that are often the ambit of the logframe and the "story of the program," which, when it is told, often relies heavily on the ToC. We assert that by developing and using the two tools as complementary, from project inception to final evaluation, we will be able to record and relay a more holistic view of the program $3 / 4$ not only what it has achieved but also how this was accomplished.

Toward this end, toward advancing further integration, we formulate five steps for how this integration might work by way of a recent real-world case example. These steps are not intended as sure-fire recipes for success to be uncritically adopted in other settings and contexts. Indeed, this type of mechanistic application cuts against the grain of what we aim for: more thoughtful and purposeful integration of logframes and theories of change. The modest aim of the five steps is simply to motivate further interest and to support further work on this important topic.

The article is structured as follows. In the first part, we consider the promises and perils of logframes and ToCs when designed and considered individually, followed by an examination of the underlying reasons that logframes and ToCs tend not to be fully integrated in their practical application. Informed by this examination, in the second part of the article, we then consider a real-world case 
example of how logframes and ToCs might be integrated in the context of international development settings and outline five steps that can be applied to further this integration process.

\section{THE PARALLEL PROMISES AND PERILS OF LOGFRAMES AND THEORIES OF CHANGE}

\section{Logical frameworks}

Since the 1970s, logical frameworks have become commonplace in international development (Rosenberg \& Posner, 1979). Reflecting their wide application, logical frameworks have been referred to by many different labels, most commonly "logframe" and "logframe matrix" (Bamberger et al., 2012). In its practical application, a logframe is ideally developed during the program design and planning stages, with revisions made throughout the implementation of the program. The logframe matrix typically takes the form of a four-by-four table, with rows for program components (activities, output, outcome, and goals) and columns for measurement information (program summary, indicators, means of verification, and risks/assumptions). A generic logframe matrix is presented in Table 1. Given the wide use of logframes, as well as their adaptation to preferences within different government and donor organizations, these categories may of course vary, but the matrix in Table 1 displays the generic structure.

There are many potential benefits of using logframes. If designed and implemented well, the logframe matrix may support program planning, management, and monitoring. As a management approach, the logframe matrix may also serve as the overarching overview and work plan for the program, guiding program implementation and management (Imas \& Rist, 2009). As a monitoring tool, the logframe may support logical framework analysis by establishing salient activities, outputs, and outcomes to be monitored; by connecting these with measurable indicators; and by identifying plausible risks and assumptions (Imas \& Rist). These are but a few of the many benefits of logframes.

Despite its many benefits, however, concerns and challenges about logframes have been raised on multiple occasions (Gasper, 1997, 2000a; Fujita, 2010). One common criticism is that the logframe approach promotes short-term program

Table 1: Generic logframe matrix

\begin{tabular}{|l|l|l|l|l|}
\hline & Summary & Indicators & Means of verification & Risks/assumptions \\
\hline Goals & & & & \\
\hline Objectives & & & & \\
\hline Outputs & & & & \\
\hline Activities & & & & \\
\hline
\end{tabular}


objectives, even if these are counter to long-term impact (Channell, 2005; Perrin, 2003; Rogers, 2008). Any reader who has worked with logframes, either reporting against it as a program management tool or trying to assess a program though the logframe lens, will likely have thought (perhaps even aloud) about this potential conflict. To be sure, and especially when used in isolation, a logframe can potentially result in perverse incentives and a focus on shorter-term achievements rather than on more distant outcomes, often obscuring contextual learning (Bamberger et al., 2012; Gasper, 2000b). As Channell observes,

Contractors fail when they do not meet various requirements for deliverables under their contracts with donor agencies. ... A contractor can be completely successful ... even if full performance has resulted in negligible benefits. (p. 17)

Moreover, and in part because the logframes are often structured around contractually obligated program objectives, logframes tend to remain static and not updated, running the risk over time of becoming a restricting "lock frame" for program learning and development (Gasper, 1997, 2000b).

Another distinct-yet related-limitation is that logframes by design do not provide information on how program objectives were reached (or not reached); the inner workings of how the program is intended to achieve the stated objectives are left undisclosed and unexamined (Eyben et al., 2008; Imas \& Rist, 2009). The simplified "linear cause-effect thinking" inherent to logframes fails to capture the complexity of change processes underlying most development programs-what Gasper (2000b) pointedly refers to as a "lack-frame." This issue exists in part because a logframe will describe "how much" but not "how" program outcomes are achieved. In the same way, the dashboard of a car indicates how fast the vehicle is travelling, how much fuel is left, how far you have travelled, and whether the engine is overheating; if you had a series of snapshots of the car dashboard, you would have a similar set of information-at this time, the car was travelling at this speed and had this amount of fuel. However, the dashboard would not (and could not) tell you how or why you travelled a specific route, which landmarks you passed, the reason for the direction you were travelling, or why you decided on the highway or a more scenic route. For that you need a different piece of equipment.

\section{Theories of change}

Theories of change speak directly to this information need. Initially introduced in the context of community-change initiatives (Connell \& Kubisch, 1998), and now widely used both inside and outside international development evaluation, the theory of change approach has and continues to be defined and deployed in many different ways (see James, 2011; Stein \& Valters, 2012; Vogel, 2012, for comprehensive reviews of ToC practices in international development settings). If we scan across this conceptual diversity, we can see that the term usually refers to both a process and a product, focusing on making explicit how program activities 
and outputs are intended to bring about a specified set of outcomes (Connell \& Kubisch; Vogel). As Vogel observes,

Some people view it as a tool and methodology to map out the logical sequence of an initiative from inputs to outcomes. Other people see it as a deeper reflective process and dialogue amongst colleagues and stakeholders, reflecting on the values, worldviews and philosophies of change that make more explicit people's underlying assumptions of how and why change might happen as an outcome of the initiative. Theory of change is at its best when it combines both approaches. (p. 3)

In both process and product, the ToC specifies how specific program components (activities and outputs) lead to a specific set of desired outcomes (Connell \& Kubisch). The better ones also include contextual conditions-within which the program is embedded - that may depress or enhance the ability of the program to generate the desired outcomes (Mayne, 2012). While there is no single format for a ToC, a generic version is for illustrative purposes provided in Figure 1. As the figure illustrates, a ToC depicts how specific program activities by way of specific program outputs connect with specific program outcomes. The connections, in the figure depicted as arrows, are in the form of assumptions, that is, hypothesized connections to be verified empirically (Connell \& Kubisch; Mayne). Considered collectively, these components comprise the underlying logic of the program. In addition, the figure also indicates that ToCs may include contextual conditions (influencing factors) that may serve to enhance or depress the program outcomes.

If designed and implemented well, ToCs can be a potentially rich source of information regarding a program's progress, intended and unintended outcomes, and causal relationships (Vogel, 2012; White, 2009). By detailing how specific

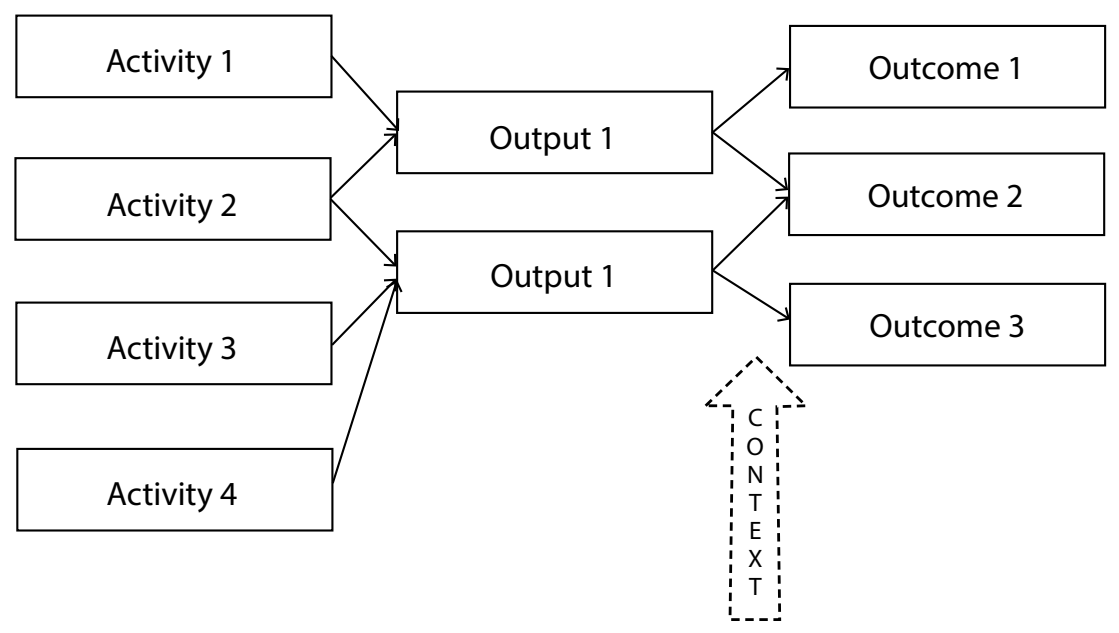

Figure 1: Generic theory of change 
activities and outputs lead to specific outcomes, the ToC supports a more finegrained analysis and understanding of how and why the program brings about the desired outcomes (or even fails to do so). As Bamberger et al. (2012) observe, ToCs may serve well to establish the most central program activities and outcomes, to identify the critical assumptions ("links") on which the success of the program is contingent, and, by extension, to guide what subsequent evaluation resources should be allocated. These are all worthwhile benefits.

The ToC, however, is not without limitations. In the context of international development, one commonly observed shortcoming is the initial development of vague and too generic theories of change (James, 2011; Vogel, 2012). There might be several reasons for this issue, including the difficult task of striking the appropriate balance between the perceived need for simplicity and the real-world context of program complexity, an admittedly difficult task (James). Another reason may emerge from the challenging nature of making explicit and detailing the wide range of assumptions underlying complex programs (Vogel). As experienced by Prinsen and Nijhof (2015), it is not uncommon for developers of ToCs to miss steps, to omit key assumptions, or simply to fail to acknowledge salient risks or other contextual conditions. Regardless of the reason, the implication of developing an overly simplified theory of change is that it reduces its ability to serve as the guiding rod for the program planning and implementation, which in turn results in a lack of interest and commitment to the ToC among implementers and decision makers - the practical value of the theory of change is depressed.

Another shortcoming emerges from the common conflation of thinking of the make up and purpose of a theory of change (Freer \& Lemire, 2016). When the underlying design and purpose of a theory of change are not well understood, or perhaps even misunderstood, the subsequent use of the ToC-by evaluators to gather data or by program staff as a tool to inform decisions-is also likely to be misapplied. This leaves decision makers, who are often searching for data regarding program progress and direction, without a nuanced, contextual understanding of program's current position. A disconnect emerges between the information called for by the ToC and the information called for by the program staff.

We also suggest that a third shortcoming might lie in the understanding and capacity of the program staff who are used to institutional reporting against quantifiable objectives, and where success is measured against the achievement or overachievement of these same objectives. Alternative measures of program implementation or outcomes, even if relevant and quantifiable, are in this context less likely to be promoted, pursued, and monitored. Programs are not assessed on their rate of failure or their innovativeness in overcoming challenges, in spite of donors' and funders' repeated verbal acknowledgement that they want to learn from failure and challenges (Channell, 2005). In our own experience of asking program staff to unpack why a course of action might not have been taken, or why program progress has fallen short of the anticipated objectives, there is an initial defensive attitude to the lack of progress or failure to achieve identified objectives. Moreover, it takes time and effort to understand why certain options were not 
chosen over others, and these decisions are often not recorded in detail. Regular revision of a ToC might assist in capturing these decisions; however, the development and subsequent revisions of a ToC can be time-consuming, and over time, at least from a program resource perspective, can become a grudge investment.

These are but a few select challenges. Considered collectively, however, and in our experience, these challenges-lack of specificity, lack of clear purpose, and a too narrow focus on program objectives-often leave the full potential of theories of change more talked about than realized.

\section{The limited interplay between logframes and theories of change}

Despite the seemingly obvious complementarity between logframes and theories of change, the potential benefits of their integration are rarely realized. While in the design phase programs are often required to develop both, rarely does a program call on one of the tools to support the other. As such, programs tend to forget about their potential mutuality: one as an internal focal guide and the other as a point of reference in a wider environment. The position we hold is that the underlying reasons for the limited integration of logframes and theories of change are rooted in conceptual conflation of the tools, the parallel ways in which the tools are developed and designed, and the differing purposes in their subsequent implementation.

For one, the similarities and distinctions between logframes and ToCs are not always clear (James, 2011; Vogel, 2012). As Vogel documents in her review of ToC practice in international development, "People find difficult to separate theory of change from the familiar logframe .... This is not surprising, as ... they come from the same family of approaches, programme theory" (p. 19). The intertwined intellectual roots, combined with the shared focus on describing the underlying logic of programs, lead to conceptual conflation of logframes and ToCs. Echoing this conceptual confusion, some practitioners come to view theories of change as "glorified logframes" (James, p. 10).

Another reason for this is to be found in the parallel ways in which program theories and logframes are often developed. In some cases, individuals who are no longer part of the program team might have developed the individual tools, perhaps as part of securing program funding, while program managers and staff are subsequently asked to deliver on and report against them (Prinsen \& Nijhof, 2015). In these situations, those implementing the program are often presented with both tools as completed items, outlining the ideal program implementation as envisioned in the early program-design stage. While there might be an evident logic, which can be read into each tool; nuances and detail, which might have formed part of the initial conceptualization, including connections between the two tools, can easily be lost, as the tools become parallel artefacts of historical thinking (Fujita, 2010).

Moreover, and even if the development of logframes and theories of change are conceptually distinct and aligned in their development, the tools are in their subsequent practical applications perceived as serving different roles and of 
reporting against different aspects of a program. As documented by James (2011), "many use theory of change to explore their organisation or programme at a broader level-to develop an overall vision and understanding of change-and then use logframes to define specific projects" (p. 10). The tools come to serve the professed needs of specific audiences, who might use them for different purposes. Even when drafted as complementary, the tools tend to develop in different directions, with different stakeholders with different purposes, growing increasingly apart and rarely reunited (Prinsen \& Nijhof, 2015).

Even in rare cases where the tools have been developed in a symbiotic process, this overlap and mutual reinforcement might not be easily understood or realized in the subsequent separation and use of each as stand-alone tools. Rather than trying to uncover any lost mysteries, the program-implementation team is caught up in the busyness of delivering the program and, when required, simply dust off the program's theory of change to show that the process remains true to its original calling-a ritualistic exercise. Invariably the tool that is most often used for external communication of program progress becomes the logframe, which displays or contains aspects that are most easily explained. In an attempt to explain progress, the program resorts to the quantifiable and focuses on logframe results. Indeed, this is the "go-to" reporting point for donors of the program as well-how best to assess the success of a program than by determining how close it is to quantifiable targets. As a result, the program staff, the donors or funders, and others within the development community lose a rich layer of analysis of how the program is working in context as well as the implementation influences and influencers (Freer \& Lemire, 2016; Mayne, 2012).

By extension, and in the use of these tools in bridging data and decision making within the program, the differing purposes are further attenuated. In many situations, as evaluators, we limit ourselves to gathering data from the logframe as it contains more quantifiable data, and the success or failure of the program is so often assessed on this basis. A theory of change-while intended as such-is rarely regarded as an interim reporting tool, with occasional final evaluations asking for a review of the ToC, assuming there was one at inception. Using the logframe as an interim reporting tool without regularly consulting or reviewing the $\mathrm{ToC}$ is comparable to thinking, "As long as I maintain this speed, I should reach my destination," disregarding the fact that you may be heading in the wrong direction or running low on fuel, finally thinking, "How did I end up here?" In taking this step, we assume that the initial logic underpinning the logframe continues to hold true, an all-too-often flawed assumption within the dynamic and fluid implementation environments of international development.

In practice, then, programs often end up with two stand-alone tools that are separate in their purpose, design, and application, whereby their mutually reinforcing integration is easily forgotten and lost. Whether because of a lack of understanding regarding the initial design or purpose of the tools, or because of a lack of appreciation of the tools' potential complementarity in implementation, the program's reporting and its evaluation are all the poorer for this situation, 
being able to report on two, related program stories when a single, integrated, and more comprehensive tale could be told.

This lack of integration comes with a number of consequences, of which two real-world examples will be provided. As one illustrative example, and as we experienced on a recent evaluation, the lack of integration may lead to fervent pursuit and progress toward quantifiable targets that might not reflect the development ethos of the overall program. Those involved in a market development program that was being evaluated, committed to a specific development methodology, realized that they were falling behind in their women-related targets. The logframe specified that the program reach a specific number of women within the stated timeframe. To their credit, the program management called for assistance and developed a gender strategy specific to their needs. However, it later emerged that while these activities contributed to the overall women-specific program targets, there was often weak adherence to the required development methodology. As evaluators we raised a few concerns, especially around the methodological commitment of the program. How did this situation arise? For a few reasons: the original women target appeared to have little basis in the contextual reality of the program, and in pursuing quantifiable targets, the program paid less attention to the quality of the impact, as required by the methodology. A well-drafted theory of change, speaking to the logframe targets, might have given voice to this concern in the program design phase, and definitely in an early program review, when the shortfall in the women-related target became obvious. Making use of the ToC as a reporting tool might also have provided more detail on the methodology of the women-specific activities, leading to questions and discussion around their rationale. These types of deliberations, grounded in the interplay between the logframe and the theory of change, could have served well to inform future iterations of the program, potentially making it more effective and efficient.

Another recent evaluation by Freer also serves well to illustrate the severe implications that may emerge from a lack of purposeful integration of logframes and theories of change. In this instance, the program was an innovative, iterative learning opportunity, funded by a range of donors, all of whom had agreed and signed off on its purpose and design. In its implementation, however, the intransigence of the logframe and the relative impotency of the theory of change were revealed. In the evaluation process it was discovered that while the innovativeness of program partners was part of the selection process, a number of partners were specifically identified due to their potential to substantially contribute to program targets. The theory of change was regarded as peripheral to this point, stating broad objectives and general process steps and providing very little detail of these real challenges faced by the program. This was a concrete example of an innovative program "playing safe" and, having realized its program targets, three-quarters of the way though implementation, broadened its selection criteria and identified partners that spoke to innovation, risk, and invention rather than to scale and numerical, target-dictated achievement. While the program moved toward and was committed to innovation and learning to this point, the realized freedom from 
logframe targets allowed program implementers to wholeheartedly pursue their envisaged ideal. A collaborative use of both tools in a mutually supportive manner might have provided the program implementers with a more flexible approach to selection of program partners or allowed them to report on qualitative indicators or on a range of quantitative metrics, in lieu of quantitative specifics.

From our perspective, then, there are several noteworthy reasons why a more purposeful integration of logframes and theories of change should be pursued. Integrating these tools in program planning and evaluation enhances both the quantitative measures that are often the ambit of the logframe and the "story of the program," which, when it is told, often relies heavily on the theory of change. Indeed, the value-added by integrating logframes and ToC more explicitly is what motivates this article. To understand what these benefits are and, perhaps more importantly, how these might be achieved, we now turn our attention to a recent theory-based evaluation, where program logframe and the theory of change were integrated.

\section{MAKING THE CASE FOR A STRONGER INTEGRATION OF LOGFRAMES AND THEORIES OF CHANGE: LESSONS LEARNED AND IMPLICATIONS FOR PRACTICE}

Freer is currently acting as evaluator on a development program focusing on regional water infrastructure crossing a number of international borders. The infrastructure is under the control of several national and international bodies, all of whom need to cooperate to ensure efficient operations. The program is working with this wide range of parties to ensure that the water infrastructure is mutually beneficial, well maintained, and efficiently operated, and to guide these bodies to use it to achieve developmental goals, such as contributing toward gender equality and poverty alleviation. The evaluation seeks to determine how and to what extent the program manages to achieve this rather ambitious developmental goal.

As part of the initial design process, the evaluation team was tasked with refocusing the suggested logframe and designing a program theory of change. This was done in collaboration with the day-to-day program staff and managers. In this process, the tools were developed in a synergistic manner, where changes in one tool influenced changes and alterations in the other. This was done deliberately by trying to determine, as just one example, how the ToC might be able to verify information on the number of beneficiaries, a key objective in the logframe. Similarly, the evaluation team tried to determine where the logframe might record data that spoke more directly to specific causal relationships, such as changes in operational or strategic focus, reflecting possible program influence. In discussions with the program donors, very few changes were approved to the logframe design, but this still allowed Freer to record this process within the ToC-that changes were suggested but rejected-and, as a result, the program has been obligated to follow a particular route to its outcomes. Freer is currently reviewing both the logframe and the ToC as part of the program's first year of implementation. 
The one-year review speaks directly to the need for a stronger integration between the logframe and the $\mathrm{ToC}$ for several reasons. As mentioned above, the water infrastructure program works with a range of institutions with different needs and varying capacities. While the logframe simply requires a quantifiable indicator as proof of progress, an initial draft of the ToC did not recognize the nuances of these institutions, suggesting that all institutions would be engaged in the same manner. A year into the program, Freer recognized that the institutional differences require subtly different, distinct steps, and as a result, when in providing evidence against the quantifiable indicator, the evaluation will be able to demonstrate these. A revised draft of the ToC takes these distinctions into account. In a similar vein, these institutional differences might require a refining of the logframe targets. The logframe itself thus becomes a more nuanced management and reporting tool, reflecting implementation distinctions.

In the fluid, less rigid world of programs in development contexts, the best a logframe can do is provide a snapshot of the program's status at a certain point in time. If you have a series of logframes for the same program, you see a series of snapshots for this program. In a dynamic, shifting world filled with individuals and institutions driven by their own agendas and objectives, such as multiple partners on a water infrastructure program, a program's progress cannot be adequately captured when it is corralled by a program logic developed and debated in an office a continent away. To determine how a program has implemented its activities or processes and how these have led to changes in people's lives, you don't need a tool; you need a toolbox. In the present example, using the ToC and the logframe in an integrated supportive manner permits insights into program progress, challenges, and refinements, giving more granular detail of what works, what does not, and why.

Moreover, the case also illustrates how the issue of perverse incentives is a challenge that pervades programs, which are bound to immoveable logframe targets. Programs allocate significant effort and resources to achieving targets, sometimes with little thought to the rationale or story underlying program design or activity implementation. A complementary use of a logframe and a ToC may go some way to reducing the tendency to take advantage of perverse incentives. In the example of the water infrastructure program provided above, by using the $\mathrm{ToC}$ as a framework to determine how a target is reached, the program might determine that in spite of high numbers of reach to institutions, the depth of impact on these institutions is not as effective as envisaged. A number of mid-course corrections could be proposed: to reduce the quantity of organizations being reached but increase the opportunity for impact; or to recognize that the impact will be influenced by a range of factors beyond the control of the program and decide to reach as many organizations as possible, recognizing the limited impact; or to try to influence some factors currently beyond program control to increase impact on the already identified organizations. Each scenario would map a slightly different path of the ToC and would require viewing the logframe targets through different 
lenses. When reviewed together, the harmonization of the two tools' stories would present a more textured program history.

If one deliberates on these nuances, the opportunities for program (and sector) learning are enhanced. A retroactive overview of program documentation would illustrate that the program opted to engage with a specific range of institutions for a variety of reasons, rather than to try and meet all of the potential organizations' needs. How much more valuable would this be than a report stating that a program achieved a numerical target? A future iteration of the program, or another initiative in a similar field, might take this lesson on board and build institutional variance into its design, potentially making it more effective and efficient.

As the example illustrates, the integration of logframes and theories of change may serve well to more accurately track program implementation rationale, give more substance and credence to program targets, and promote a more textured and accurate program history. The challenges, then, for program designers, donors, funders, implementers, and evaluators can be framed by the following questions:

- How to build the complementarity of the tools at each stage of the program, from conceptualization through to design and implementation?

- How to draw on both tools to supplement and complement the information contained in the other?

Informed by the integration of logframes and ToCs in the preceding case, we propose five steps that can be taken to advance this type of integration. The purpose of these suggested actions, developed on the basis of a real-world example, is to provide food for thought and a possible scaffolding for integrating the program tools in other contexts, rather than to prescribe a blueprinted process.

\section{Step one: Recognize the distinct purposes of each tool}

The first step toward a stronger integration is for various stakeholders to understand the purpose and functionality of both tools, as well as their respective strengths and weaknesses. Logframes are generally well understood in terms of purpose and reporting, but their weaknesses might be less explicit. We have already mentioned a few of these weaknesses above, including unidimensional measurement and an assumed logic that imposes itself through implementation.

Theories of change, in contrast, are less well understood but are common parlance in international development circles, with appropriate definitions, purposes, and uses regularly being debated. Aside from the weaknesses that can arise from this lack of clear parameters (something that the logframe, by its very structured nature, has managed to eliminate), we need to understand that a theory of change takes as its background the social, economic, political, and cultural characteristics of the program environment and tries to distil the most pertinent aspects that either will be influenced by or will influence the program. 


\section{Step two: Recognize that in spite of their different purposes, the tools can be used in a complementary fashion}

Program implementers (and donors) need to move away from reliance on the logframe to measure success and perhaps instead take to heart the common adage, "Not everything that counts can be counted, and not everything that can be counted counts." The planned impact that the program has on the targeted population is important and is reflected in logframe reporting. The way in which this impact is implemented and its intended and unintended consequences are similarly important, but this process cannot be quantitatively measured and reflects a different facet of the program's success.

Programs report regularly on their progress. In many cases, changes to or implications of the planned implementation are explained, sometimes in great detail. Donors have often been participants in this ongoing conversation and agree with the recorded decision. However, rarely are these changes or implications mapped against the program theory of change, with alternatives (and their implications) to the planned route explained. If we intend developmental programs to be replicable or to learn from their failure, then recording these decisions should receive more attention. "How?" and "Why?" should be asked and answered regularly and should have similar weight to the current refrain of "How many?" and "How much?"

\section{Step three: Seek complementarity at the outcome level}

In the water infrastructure example, program outcomes request quantifiable proof of institutional initiatives. However, as mentioned, there is a range of institutional capacities with which the program is working, increasing the complexity of achieving these targets. The program might choose to work with the easier but less strategic organizations. Or it might work with more demanding and more strategic institutions. As a result, it might fail to achieve its logframe targets but lay solid groundwork for future institutional arrangements. Should the program "fail" for choosing a more difficult but more considered institutional partnership?

These options of either working with more difficult but strategically more important organizations or choosing the easier "low hanging fruit" (and the implications of such a choice) need to be recorded. One of the places to do so is in aligning the logframe outcomes with the program theory of change, providing a map of alternative routes and explaining the choice to follow one over the other.

\section{Step four: Revise the tools in tandem}

To gain any benefit from the complementarity of the tools, they should be brought into play at the same time, both for reporting and for revision. One way of ensuring this is to regularly review the theory of change, at least as often as the logframe-annually for many programs. The tools need to be finalized in conjunction with one another, and changes to one tool should be checked for implications against the other. While one small change might not need a corresponding change 
on the second, a series of small changes, incremental on their own, might have a profound impact on the second tool.

During the review process, we need to ascertain whether the planned theory of change was followed, whether the program was influenced or was an influencer, and the implications of these for the program's quantifiable targets, recording any deviations to the planned process. Similarly, a logframe review of the program's progress should try to uncover reasons for achievement (or under- or overachievement) and map these answers to the theory of change. Questions such as "At what point did we realize that ...?" and "Did this decision help (or hinder)....?" begin to weave the reviews together.

In some cases, decisions reflecting questions like these may lie buried in program progress reports or meeting minutes, justifying a particular decision, but the surrounding context and reasons (and dissenting opinions) might not be recorded or reflected in the program theory of change. As a result, at the end of a program, when we ask, "How did we end up here?," we have little institutional memory on which to draw, weakening our evaluation with statements starting with "it is possible" and "we reasonably suggest."

\section{Step five: Call for both tools to present evidence when making strategic decisions}

This, we think, will possibly be the most difficult step for both implementers and donors to adopt. But it might also be the most important. Quantifiable indicators often drive decisions regarding success and failure. We do not deny the importance of these indicators but rather point out that in some cases, alternative quantifiable indicators can be presented, if the opportunity arises. Programs not achieving set targets have been closed when, in some cases, alternative options of quantifiable targets could have been considered. Instead of building on these "alternative successes," closed programs negate the sunk costs of infrastructure and undermine the irrecoverable costs of established relationships.

Development programs regularly need to make strategic decisions about their future-to expand, withdraw, close out, extend a timeframe, and so on. Some of these decisions require evidence of progress, provided by logframe reporting. What is often not called upon to lend context and colour to the stark numbers is progress (or the lack thereof) against the theory of change. At worst, calling for and reviewing this evidence in parallel to logframe evidence would provide no added value. At best, an extra source of substantiated explanatory evidence would add value to the process, give alternative explanations, and possibly provide alternative options for the decision makers.

Given the number of international development programs that are currently underway, we should regularly ask a range of questions of them. During program implementation we often ask, "How fast did we get here?" and "How much did it cost?" Only on completion do we think about "Was that the best route?" and "Is this our planned destination?" We suggest that we might want to ask ourselves these (and other) questions more often during implementation, as well as on 
program completion, and that one way of doing so might be to use program management and evaluation instruments as complementary tools providing related evidence to better serve our ultimate developmental goal. Toward this end, stakeholders, from donors to designers to implementers, need to understand the purpose of both tools and to call on their use, in order, in the case of the implementers, to report against progress, and in the case of the donors, to hold the implementers to account.

\section{CONCLUDING THOUGHTS}

Development programs take place in complex environments, and developmental goals are growing in complexity and interconnectedness. Yet the tools we use to plan, monitor, report on, and evaluate these same programs are stand-alone and static, some little evolved from their initial debut almost 50 years ago. As planners, as donors, as implementers, and as evaluators, in our commitment to development we should recognize the limitations that these tools impose and seek to overcome them. One possibility is to view the tools differently. Rather than seeing them as authorities to which the program must prostrate itself, we should view them as collaborative and supportive tools that the program can utilize in parallel in order to more fully document and explain its implementation. Used collaboratively, a program logframe and its theory of change can track not only the progress and speed at which a program is travelling but also its direction and whether it has encountered a more scenic route. The five steps we outline above suggest one method of establishing this collaborative working relationship.

\section{REFERENCES}

Bamberger, M., Rugh, J., \& Mabry, L. S. (2012). Realworld evaluation: Working under budget, time, data, and political constraints. Thousand Oaks, CA: Sage.

Channell, W. (2005). Lessons not learned: Problems with Western aid for law reform in postcommunist countries. Carnegie Papers: Rule of Law Series, 57. Retrieved from https:// carnegieendowment.org/files/CP57.Channell.FINAL.pdf

Connell, J. P., \& Kubisch, A. C. (1998). Applying a theory of change approach. In K. Fulbright Anderson, A. C. Kubisch, \& J. P. Connell (Eds.), New approaches to evaluating community initiatives (Volume 2): Theory, measurement, and analysis (pp. 15-45). Washington, DC: The Aspen Institute.

DFID. (2011). Guidance on using the revised Logical Framework. DFID Practice Paper. London, England: Department for International Development (DFID). Retrieved from https://www.gov.uk/government/publications/dfid-how-to-note-guidance-onusing-the-revised-logical-framework

Eyben, R., Kidder, T., Rowlands, J., \& Bronstein, A. (2008). Thinking about change for development practice: A case study from Oxfam GB. Development in Practice, 18(2), 201-212. https://doi.org/10.1080/09614520801898996 
Freer, G., \& Lemire, S. (2016, April). “The keystone node approach: Conducting theory based evaluations of complex programmes." United Kingdom Evaluation Society, London, England.

Fujita, N. (Ed.) (2010). Beyond logframe: Using systems concepts in evaluation. Tokyo, Japan: Foundation for Advanced Studies on International Development. Retrieved from https://www.fasid.or.jp/_files/publication/oda_21/h21-3.pdf

Gasper, D. (1997). Logical frameworks: A critical assessment managerial theory. Pluralistic Practice Working Paper 264. The Hague, Netherlands: Institute for Social Studies.

Gasper, D. (2000a). Evaluating the "logical framework approach" towards learning-oriented development evaluation. Public Administration Development, 20(1), 17-28. https://doi. org/10.1002/1099-162X(200002)20:1<17::AID-PAD89>3.0.CO;2-5

Gasper, D. (2000b). Logical frameworks: Problems and potentials. Institute of Social Studies. Retrieved from http://www.academia.edu/6665953/Logical_Frameworks_Problems_ and_Potentials

Hummelbrunner, R. (2010). Beyond logframe: Critique, variations, and alternatives. In N. Fujita (Ed.), Beyond logframe: Using systems concepts in evaluation (pp. 1-33). Tokyo, Japan: Foundation for Advanced Studies on International Development. Retrieved from https://www.fasid.or.jp/_files/publication/oda_21/h21-3.pdf

Imas, L. G. M., \& Rist, R. C. (2009). The road to results: Designing and conducting effective development evaluations. Washington, DC: World Bank.

James, C. (2011). Theory of change review: A report commissioned by Comic Relief. Comic Relief. Retrieved from http://www.actknowledge.org/resources/documents/James_ ToC.pdf

Mayne, J. (2012). Contribution analysis: Coming of age? Evaluation, 18(3), 270-280. https://doi.org/10.1177/1356389012451663

Perrin, B. (2003). Implementing the vision: Addressing the challenges to results-focused management and budgeting. Paris, France: OECD. Retrieved from http://www.oecd.org/ dataoecd/4/10/2497163.pdf

Prinsen, G., \& Nijhof, S.(2015).Between logframes and theory of change: Reviewing debates and a practical experience.Development in Practice, 25(2),234-246. https://doi. org/10.1080/09614524.2015.1003532

Rogers, P. (2008). Using programme theory to evaluate complicated and complex aspects of interventions. Evaluation, 14(1), 29-48. https://doi.org/10.1177/1356389007084674

Rosenberg, L. J., \& Posner, L. D. (1979). The logical framework: A manager's guide to a scientific approach to design and evaluation. USAID.

Stein, D., \& Valters, C. (2012). Understanding 'Theory of Change' in international development: A review of existing knowledge. The Asia Foundation and the Justice and Security Research Programme. Retrieved from http://www.theoryofchange.org/wp-content/ uploads/toco_library/pdf/UNDERSTANDINGTHEORYOFChangeSteinValtersPN. pdf

Vogel, I. (2012). Review of the use of 'Theory of Change' in international development. DFID. Retrieved from https://assets.publishing.service.gov.uk/media/ 57a08a5ded915d3cfd00071a/DFID_ToC_Review_VogelV7.pdf 
White, H. (2009). Theory-based impact evaluation: Principles and practice. International Initiative for Impact Evaluation. Working Paper 3. Retrieved from http://www.3ieimpact. org/media/filer_public/2012/05/07/Working_Paper_3.pdf

\section{AUTHOR INFORMATION}

Gordon Freer is a lecturer in international relations at the University of the Witwatersrand, Johannesburg, South Africa.

Sebastian Lemire is a postdoctoral scholar in the Social Research Methodology Division in the Graduate School of Education and Information Studies, University of California, Los Angeles. 